\title{
CORRESPONDENCE
}

\section{European bounty for taxonomists}

Non-professional taxonomists have been responsible for describing more than half of the animal species discovered in Europe from 1998 to 2007 (see also Nature 467, 788; 2010). The extraordinary current rate of description of new species makes Europe an unexpected frontier for biodiversity exploration.

The Fauna Europaea database (www.faunaeur.org), released in 2004, lists more than 125,000 European species of multicellular terrestrial and freshwater animals. More than 700 new species are described each year in Europe - four times the rate of two centuries ago. However, we have not yet reached saturation in the inventory of European fauna, and we cannot accurately estimate the total number of species living in the continent's ecosystems.

The unprecedented rate of species description has depended heavily on the scientific contribution of unpaid scientists (non-professional and retired professional taxonomists). More attention should be given to ways of enhancing this formidable workforce.

There is an urgent need for an effective policy-supported business plan to complete the biodiversity inventory at European and national levels, preferably targeting speciesrich and less-charismatic groups such as mites, rove beetles, micro-wasps and nematodes. Amateurs could be readily integrated into such a framework of defined and coordinated objectives.

The future of amateur taxonomy also depends on incorporating molecular techniques, either through formal training or through collaboration between molecular-oriented professionals and morphologyoriented citizen scientists. Benoît Fontaine on behalf of 51 co-authors ${ }^{*}$, Muséum National d'Histoire Naturelle, France. fontaine@mnhn.fr

${ }^{*}$ A full list of signatories is available online at $h t t p: / / d x$.doi. org/10.1038/468377a

\section{Innovation in Europe - three questions}

Three long-standing questions still need to be addressed to stimulate innovation in the European Union (Nature 467, 1005; 2010).

First, to what extent can governments make informed choices about which areas should be stimulated by public (and private) funding of research and development (R\&D)? Governments generally lean towards areas with a strong past performance rather than favouring those with a promising future. Are public agencies or any other organization - capable of picking future winners?

Second, assuming that governments have the capability and remit to select promising areas, the next question is whether the European Union is the proper level for policy interventions. To put it another way: to what extent do European-wide innovation partnerships yield better products than national or regional ones? This everlasting debate becomes even more relevant in the implementation and feasibility of large-scale $\mathrm{R} \& \mathrm{D}$ projects. Perhaps one should accept a variety of spaces for public R\&D intervention - some sectors require international research and innovation policies, whereas others are the realm of regional policies.

Third, there is the issue of how to organize innovation projects that address societal issues. You rightly point out the challenges of coordinating multiple-actor constellations. However, science and technology studies teach us that proactively involving stakeholders from different backgrounds and disciplines can be beneficial to the 'responsible' steering, utilization and implementation of R\&D.

Wouter Boon, Gaston

Heimeriks Utrecht University, the Netherlands.

w.boon@geo.uu.nl

\section{Misreporting: a glowing report}

As a former science writer for several UK national newspapers, I commend Simon Lewis for his balanced and valuable analysis of how to deal with misreporting (Nature 468, 7; 2010).

Lewis avoids the common error of assuming that the bylined journalist was responsible for the headline or the final text. As I know all too well, stories can be extensively rewritten without being referred back to the named author. Complaining about this practice is regarded as naive and career-limiting.

His experiences show how one can use the rivalries that exist between newspapers to obtain some redress for misreporting. Newspapers delight in reporting egregious examples of misreporting by rivals.

Thus, in approaching the UK newspaper The Guardian, Lewis targeted his complaint about the original Sunday Times report perfectly. I am glad that Lewis was able to gain some redress. I am also grateful to him for reminding me how good it is to be out of the newspaper business. Robert Matthews Aston University, UK. rajm@physics.org

\section{Reef technology to} rescue Venice

Rachel Armstrong and Neil Spiller suggest that Venice's sinking foundations might be supported by an artificial reef grown using 'protocells' that precipitate limestone from sea water (Nature 467, 916-918; 2010). The technology already exists to grow structures rapidly from sea water, and this could be applied in Venice immediately.

'Biorock' electrolysis of sea water has been used for nearly 35 years in more than 20 countries to grow limestone structures of any size and shape in sea water and brackish water (W. Hilbertz IEEE J. Oceanic Eng. 4, 94-113; 1979).

Biorock products have a load-bearing strength of up to 80 newtons per square millimetre (80 megapascals), around three times higher than concrete made from ordinary Portland cement. Corals and oysters grow faster and survive environmental stress better on Biorock structures. These have helped to restore severely eroding beaches on atoll islands within just a few years (for example, see go.nature.com/ buyqjk).

Thomas J. Goreau Global Coral Reef Alliance, Massachusetts, USA. goreau@bestweb.net

\section{CONTRIBUTIONS}

Submissions to

Correspondence may be sent to correspondence@ nature.com after consulting the author guidelines at http://go.nature.com/ cMCHno. They should be no longer than 350 words. Readers are also welcome to comment online on anything published in Nature: www.nature.com/ nature. 